九州大学学術情報リポジトリ

Kyushu University Institutional Repository

\title{
Detection of Slums from Very High-Resolution Satellite Images Using Machine Learning Algorithms: A Case Study of Fustat Area in Cairo, Egypt
}

Salem, Muhammad

Graduate School of Human-Environment Studies, Kyushu University

Tsurusaki, Naoki

Faculty of Human-Environment Studies, Kyushu University

Eissa, Ahmed

Faculty of Urban \& Regional Planning, Cairo University

Osman, Taher

Faculty of Urban \& Regional Planning, Cairo University

https://doi.org/10.5109/4102491

出版情報 : Proceedings of International Exchange and Innovation Conference on Engineering \& Sciences (IEICES). 6, pp. 219-224, 2020-10-22. Interdisciplinary Graduate School of Engineering Sciences, Kyushu University バージョン:

権利関係 : 


\title{
Detection of Slums from Very High-Resolution Satellite Images Using Machine Learning Algorithms: A Case Study of Fustat Area in Cairo, Egypt
}

\author{
Muhammad Salem ${ }^{1,2}$, Naoki Tsurusaki ${ }^{3}$, Ahmed Eissa $^{2}$, Taher Osman ${ }^{2}$ \\ ${ }^{1}$ Graduate School of Human-Environment Studies, Kyushu University, Japan, ${ }^{2}$ Faculty of Urban \& Regional Planning, \\ Cairo University, Egypt, ${ }^{3}$ Faculty of Human-Environment Studies, Kyushu University, Japan. \\ Corresponding author email: m.salem@kyudai.jp
}

\begin{abstract}
Slums are a global urban challenge, particularly in big cities in most developing countries where they are growing faster than governments control. However, detection of slums is a big challenge for such countries due to fast growing there and difficulty of field survey. To address this challenge, this study uses a novel method to detect slums from very high-resolution (VHR) satellite images using machine learning algorithms and roads network derived from OpenStreetMap. This method has been applied to Fustat Area in the center of Cairo, Egypt where slums highly exist. The result of this study has detected eight slums with areas that ranged from 2.4 ha to $28.3 \mathrm{ha}$. The accuracy of the result has been verified by the kappa index which showed a high accuracy of 0.93. The results of this study are important for planners and decision makers to help them in developing such areas.
\end{abstract}

Keywords: Detection; Slum; Machine Learning; Very High-Resolution Satellite Image; Cairo

\section{INTRODUCTION}

During recent decades, slums have been emerged within and around big cities, particularly in developing countries $[1,2]$. Consequently, numerous problems have occurred due to the fast growing of such areas [3,4]. Hofmann et al. [5] argue that every day a new house established in a slum faster than government monitoring. Salem et al. argue that during the unusual circumstances the rate of slums growth is increasing incredibly, for instance, in Egypt, during the Egyptian civic revolution in 2011 the rate of slums growth has increased three times [6].Thus, the detection of slums became a major concern and challenge for authorities of many developing countries. According to the United Nations, 900 million people live in slums and this number expected to grow up to three billion by 2050 if more effective measures are not put in place to manage slum populations [7].

In general, the slum is an area of a city usually heavily populated characterized by poverty, poor housing conditions and incomplete infrastructure [8]. Slum houses vary from shanty houses to professionally built dwellings without plans or regulation. However, the roads network generally is very poor and most of the roads are narrow with dead-ended [9].

Detection of slums is considered an important issue where it assists in producing global statistics on slums in support of Sustainable Development Goals (SDGs), particularly Goal 1: No poverty, Goal 6: Clean Water and Sanitation and Goal 11: Sustainable Cities and Communities [10-12]. During the last decades, detection of slums is done through field survey which takes an extensive amount of effort, time and money [13]. Recently, remote sensing techniques based on satellite images have been used to detect slums and have proved a significant success [14-17]. In addition, these techniques overcome the limitations of field surveybased data collection methods, which are often interrupted by access difficulty (e.g., the objection of local residents, the limited availability of staff, and unsafe areas [14].

Satellite images are powerful and cost-effective source for detecting the temporal and spatial dynamics in cities. The density and rapid availability of satellite images help to monitor the land surface in unprecedented detail and increasingly in near real-time. However, using lowresolution satellite images in remote sensing techniques is hardly capture the characteristics of slums [13] where the building extraction is difficult to implement in the very high-density area [14], and the narrow roads are disappearing [2]. Therefore, this study depends on VHR satellite images which provide the required spatial accuracy to classify and mapping slums $[14,18]$.

The emergence of VHR satellite images has led to the development of used techniques in analyzing its big data, most notably is machine learning [19]. Machine learning (ML) is the fastest-growing trend in big data analysis. ML allows computational models that are composed of multiple processing layers to learn representations of data with multiple levels of abstraction. Very recently, a few researchers started to use ML techniques in detection and monitoring of slums and have achieved significant success $[16,19,20]$. Hence, ML can be considered the state of the art for detection and monitoring of slums due to its ability to generate accurate and realistic results from satellite images [16]. ML algorithms have the highest reported accuracies and allow working with large indicator sets in a computationally efficient manner [5].

This study uses a novel method to detect and monitor slums from very high-resolution (VHR) satellite imagery using Machine learning (ML) algorithms and roads network derived from OpenStreetMap. This method can be used to identify and map slums at any of its stages whether in the beginning or growing or densification stage. In addition, to monitor the growth of different parts of the city that are likely to be transformed into slums in the future. VHR satellite images will provide the required 
data (Big Data) for the study area through analyzing it using remote sensing techniques.

It is noticeable to mention that slum areas consist of high diversity in terms of morphological characteristics across the globe where the characteristics of slums can vary from one location to the other. So, professional expertise is necessary to define suitable rules for the designed algorithm based on morphological characteristics for each case study [19].

Cairo is the capital of Egypt and the biggest city in the Middle East and North Africa [21]. Due to rapid growth of population and lack of formal housing, the slums have spread in the city [22]. Despite the accelerated growth of slums, the government of Egypt adopted the policy of negligence toward them [23]. As results, the information about these slums became unavailable or inadequate,

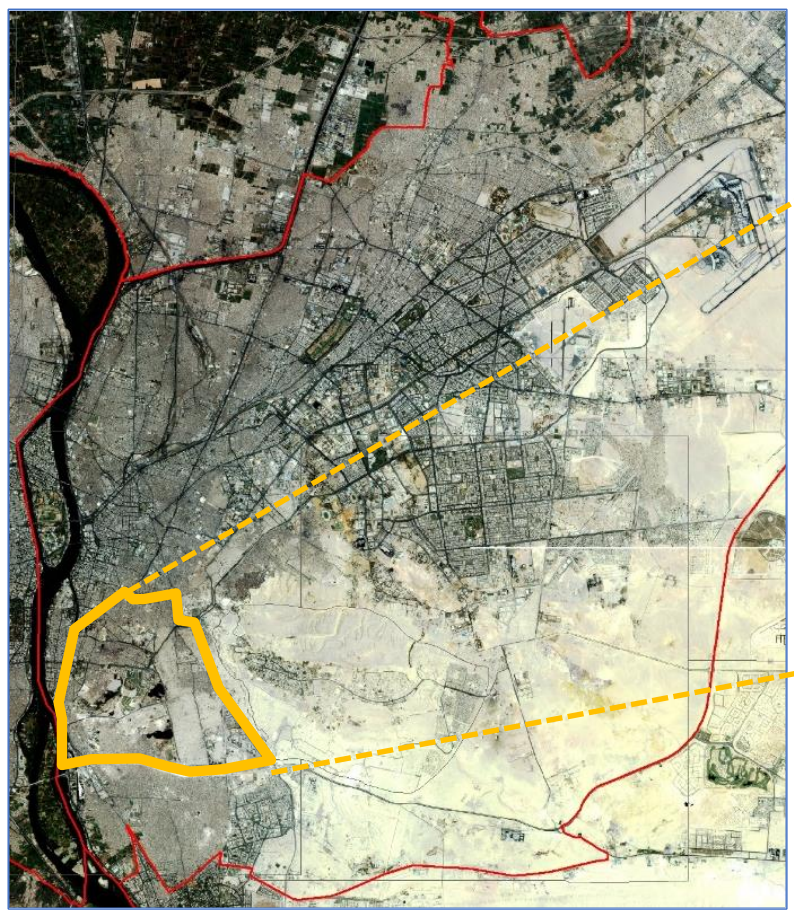

Cairo particularly their locations and area. Thus, this study seeks to detect the slums in the center of Cairo which known as Fustat area depending on the derived information from VHR satellite images and OpenStreetMap using ML algorithms.

\section{MATERIALS AND METHOD}

\subsection{Study Area}

The study area is Fustat area which is located in the center of Cairo with a total area of approximately 17,000 hectares and total population amounted to approximately 700 thousand inhabitants [24]. The study area includes a variety of both planned areas and unplanned areas. Fig. 1 shows the location of study area in Cairo.

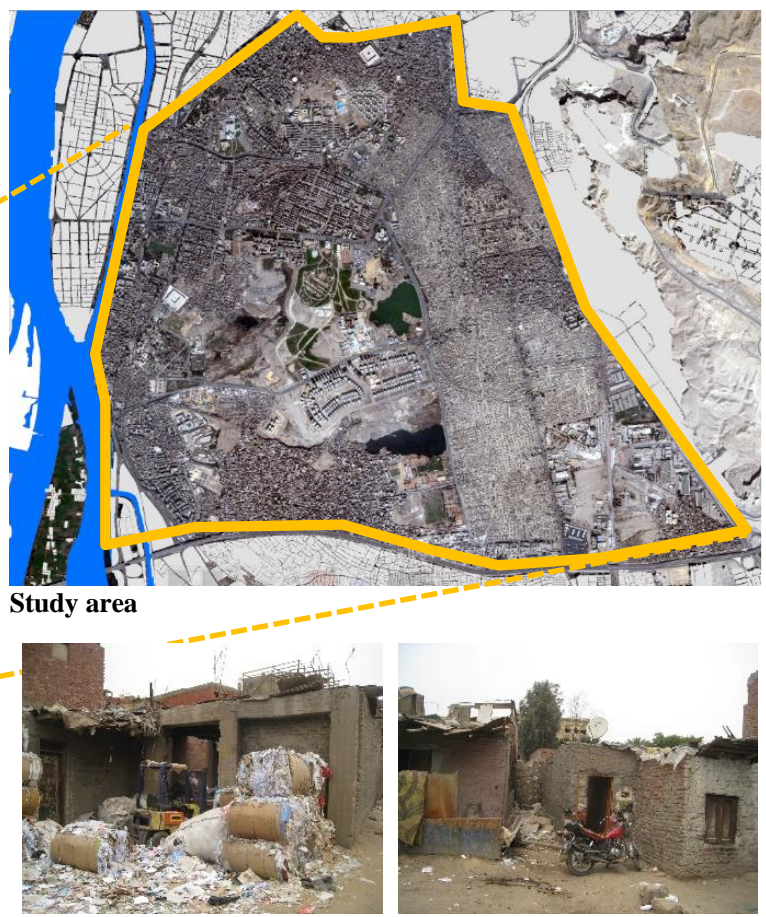

Samples of slums in the study area

Fig. 1. Study area in the central of Cairo, Egypt

\subsection{Data}

The data used in this study are, two VHR satellite images; QuickBird-2 satellite image (Three bands) 1-meter resolution per pixel, and KOMPSAT-3 satellite image (four bands) 70-centimeter resolution per pixel. In addition, a shapefile of roads network was derived from OpenStreetMap (OSM). Error! Reference source not found. shows the details of dataset types and sources.

Table 1. Dataset types and sources

\begin{tabular}{llll}
\hline \hline \multicolumn{1}{c}{ Dataset } & \multicolumn{1}{c}{ Source } & \multicolumn{1}{c}{ Res. } & \multicolumn{1}{c}{ Date } \\
\hline QuickBird-2 & Digital Globe & $1 \mathrm{~m}$ & May 2006 \\
KOMPSAT-3 & LANDINFO & $70 \mathrm{~cm}$ & Jun 2019 \\
Roads Network & OpenStreetMap & - & Oct 2019 \\
\hline \hline
\end{tabular}

\subsection{METHOD}

2.3.1 Defining morphological characteristics of slums

Previous studies related to slums have highlighted a set of morphological characteristics which are very common to exist in slums [25]. UN- Habitat has reported that most of buildings in slums have poor construction materials [26]. Wurm et al [8] argued that roads network in slums are organic and has irregular arrangements. Devyani et al. [27] mentioned that most of buildings in slums are less than 3 floors due to poor construction materials. Verma et al. [28] reported that slums in developing countries have high density and are often hazardously exposed areas .

During the last decades many attempts from experts to delineate the slums from the maps based on their expertise [29,30]. However, it became difficult to recognize it in the metropolitan cities [25]. Machine learning can do that easily by programming a model includes all required information (all slums characteristics) [27].

\subsubsection{Image Processing}

This study uses object-based image analysis (OBIA) technique for land use land cover (LULC) information extraction from a very high-resolution satellite image. The study used a neighbour classification (NN 
Proceeding of International Exchange and Innovation Conference on Engineering \& Sciences (IEICES) 6 (2020)

classification) technique in ECognition software because it has the advantage of using multiresolution segmentation in combination with supervised classification [20,31].

\subsubsection{Extracting roads from OpenStreetMap}

OpenStreetMap (OSM) is considered the most popular Volunteered Geographic Information (VGI) project which received large attention from GIS community [2]. OSM produces free vector geographic databases for roads network based on field surveys. In this study, we extracted roads network in study area form OSM database to conduct the related analysis of roads characteristics in slums.

2.3.4 Detection of slums in the study area

Based on the characteristics of slums which extracted from the literature review, the study has built the model of detection of slums in the study area as follows:

1. From VHR satellite images and using object-based image analysis (OBIA) technique, the study detected the land use and land cover (LULC) in the study area. Then, the study extracted buildings from the previous map of
LULC. According to characteristics drawn from the literature review and professional expertise. Most of the buildings in slums in Cairo have irregular shapes and their area less than $100 \mathrm{~m} 2$. We used ML algorithms to highlight all buildings falling under such rules.

2. From OSM, the study extracted roads network in the study area. Then, we focused on local roads which less than 8 meters wide. We used ML algorithms to classify local roads with dead-end and random roads which lacked hierarchy.

3. We used ML algorithms for overlapping the previous selections to detect the slums zones which falling under such rules. Some errors have occurred during the analysis. So, we changed the parameters of these rules many times until we got the best results.

4. We verified the results of this model by checking a set of objects randomly in Google earth software and conducting a field survey in the study area.

5. We have drawn the slums map. Fig. 2 shows the methodology of study.

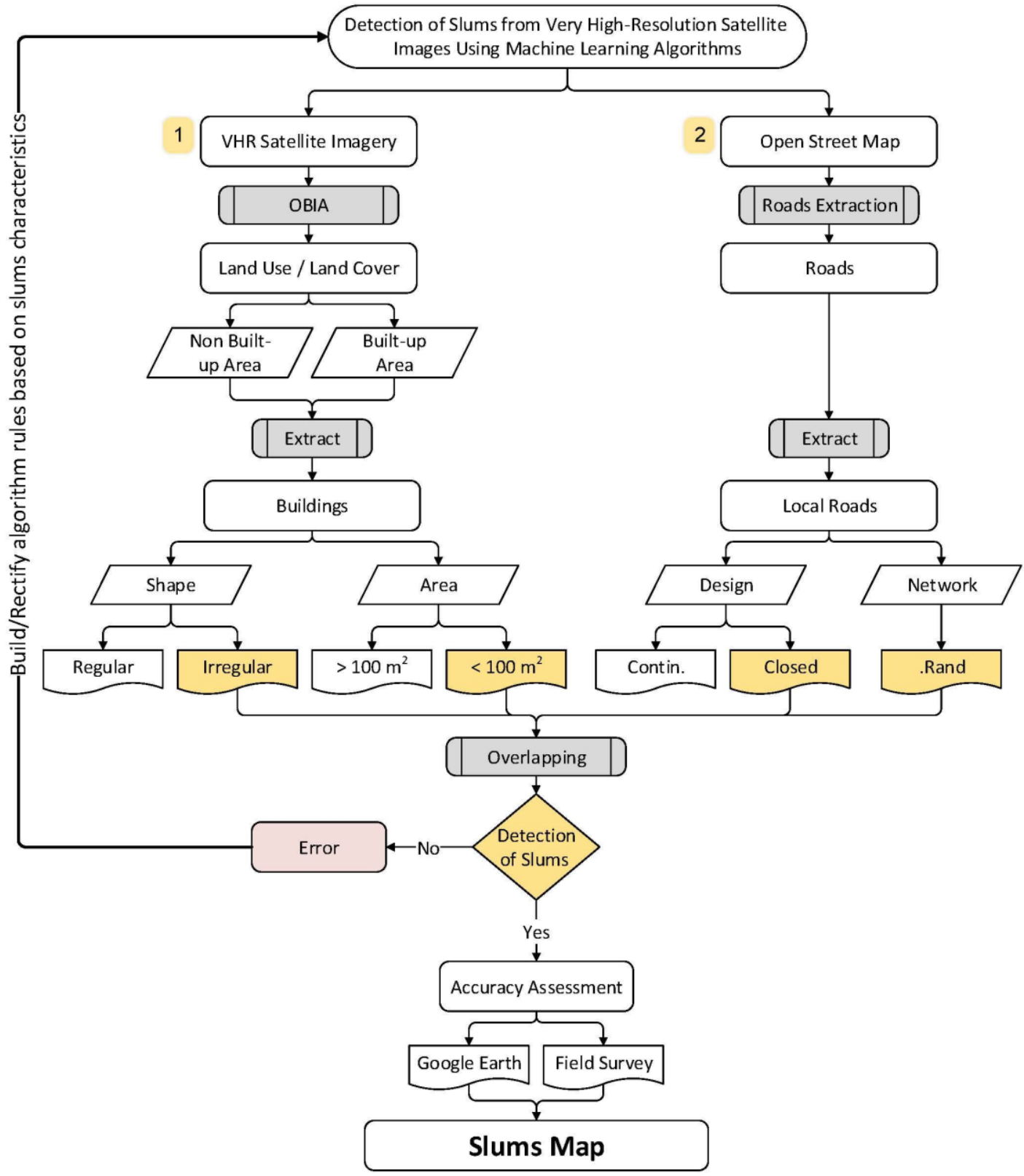




\section{RESULTS AND DISCUSION}

\subsection{Segmentation Stage}

Multi resolution segmentation algorithm was used in eCognition software at segmentation stage. Fig. 3. shows image segmentation of part of the study area.

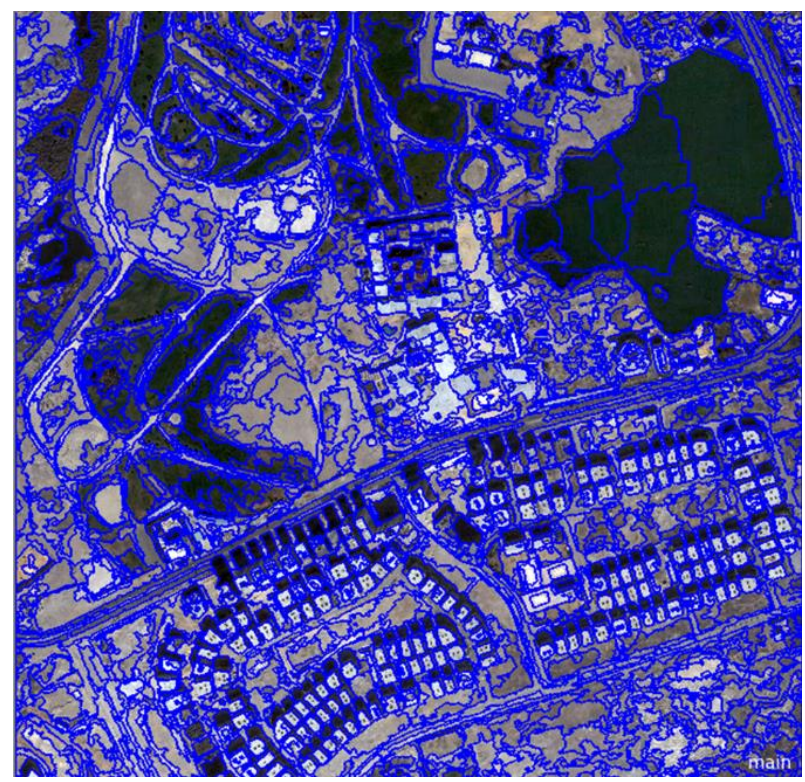

Fig. 3. Image segmentation of part of the study area

\subsection{Supervised classification}

A supervised classification technique was conducted for the image classification process using 100 training sites in each class to represent five land use land cover (LULC) types: buildings, cemeteries, vacant, green area and water. Then, 10 random points were selected from each class and compared digitally with the corresponding objects of the original images in Google Earth as reference data. Fig. 4. shows the results of the classification.

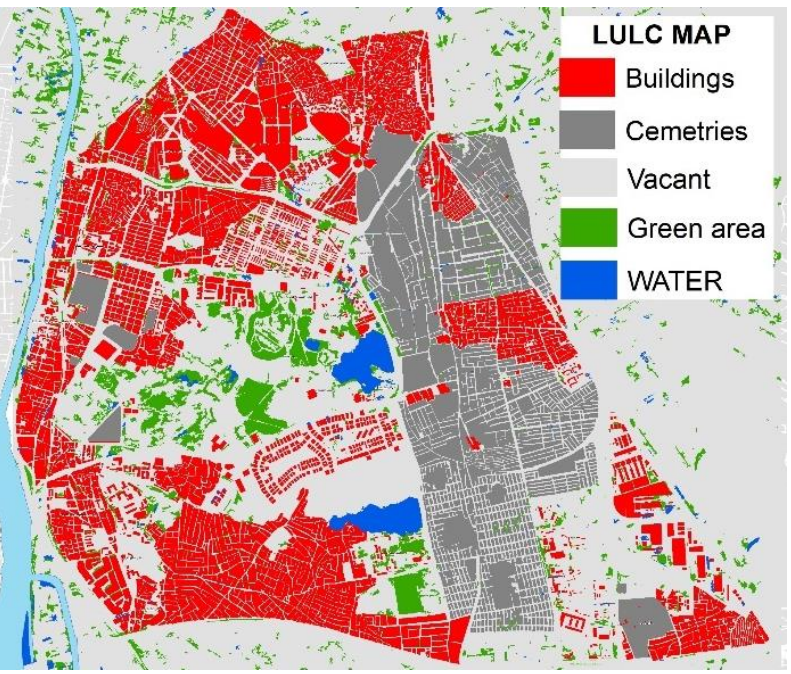

Fig. 4 Results of classification in the part of study area

The total accuracy was estimated by producing an error classification matrix for each class. The Kappa index was applied to compute the accuracy, which showed accuracy rates of 0.89 and 0.93 for 2006 and 2019, respectively.

\subsection{Extract roads of study area from OpenStreetMap}

Roads network of study area has been extracted from
OpenStreetMap to apply the designed rules, as shown in fig 5 .

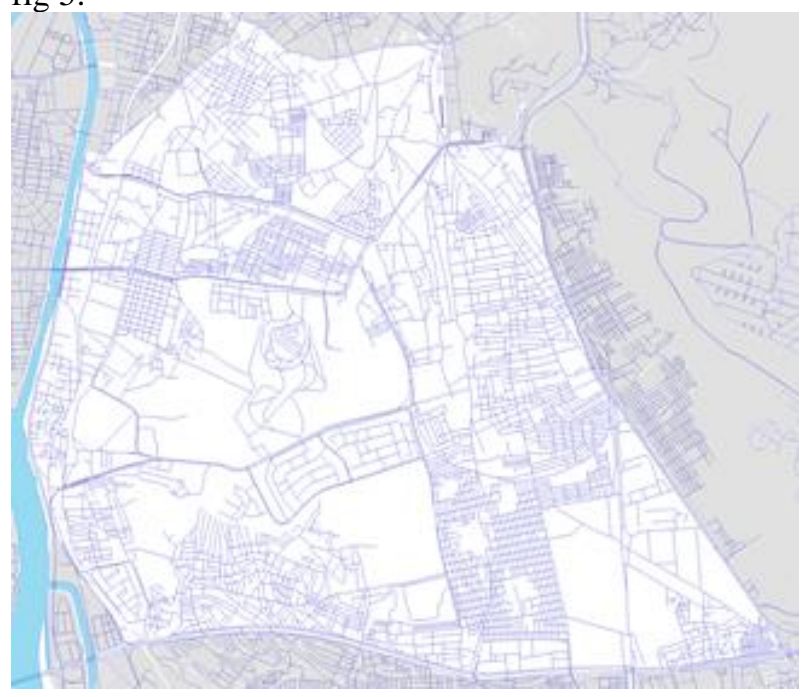

Fig. 5 Roads network of study area

\subsection{Detection of slums in Fustat area}

Based on the methodology early mentioned, we have detected 8 slums in the study area that comply with the designed model. The area of such slums ranges from 2.4 ha to 28.3 ha with a total area of 105.3 ha, as shown in fig. 6 .

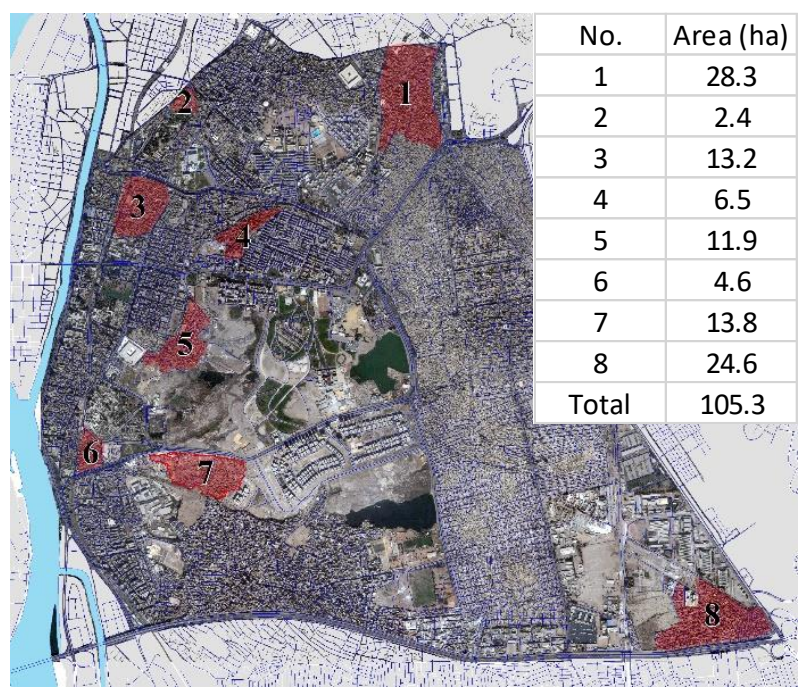

Fig. 6 The detected slums in the study area

This result is compatible with the outcome of the study of the informal area by Informal Settlements Development Fund (ISDF) in Egypt which defined 6 areas of the 8 detected area as unsafe slums in Cairo [32]. In addition, the results showed over than $80 \%$ of matching with results of Sims [33], GTZ [22], Shawn [34] and Kenawy [35] who depended mainly on field survey in their studies, which prove the high accuracy of our results in this study.

The used methodology in this study can be developed to monitor the growth of slums through detecting the slums in different years and monitor the change of the area in each slum.

\subsection{Limitation}

Although the results of the detection of slums from VHR satellite images were largely precise, there is some limitation to apply the same method in other areas. For 
instance, there is a shortage of spatial and temporal coverage by VHR imagery across the globe[36]. There developing countries in Asia and Africa and South America that have no availability VHR satellite images such as Congo, Afghanistan, and Ecuador [14].

The number of extracted buildings in the case study (Fustat area) reached to more than 63,000 building which generated big data during the analysis. This big data took a long time during the analysis and applying the models. This issue can represent a big challenge if the study extended to the whole city of Cairo or applied to any other metropolitan city.

\section{CONCLUSION}

This study has used data driven from VHR satellite images and OSM to detect slums in the Fustat area in the center of Cairo. First, the study has extracted the characteristics of slums from the literature review and previous studies. Then, the study used the extracted characteristics to build the methodology of detection. ML algorithms have been used to recognize the defined characteristics of slums from the satellite images and OSM. Consequently, the study detected 8 slums in the study area that area ranged from 2.4 ha to 28.3 ha. Moreover, the methodology of this study can be developed to monitor the growth of slums.

\section{REFERENCES}

[1] Mike Davis, Planet of Slums, Verso, London, UK, 2006.

[2] M.R. Ibrahim, H. Titheridge, T. Cheng, J. Haworth, predictSLUMS: A new model for identifying and predicting informal settlements and slums in cities from street intersections using machine learning, Comput. Environ. Urban Syst. 76 (2019) 31-56. https://doi.org/10.1016/j.compenvurbsys.2019.03.0 05 .

[3] M. Salem, N. Tsurusaki, P. Divigalpitiya, Fractal Dimension as A Descriptor of Expansion of PeriUrban Areas in Greater Cairo Region, in: 3rd Int. Exch. Innov. Conf. Eng. Sci., Graduate School of Engineering Sciences, Kyushu University, Fukuoka, Japan, 2017: pp. 115-117. https://doi.org/10.15017/1906390.

[4] C. Lemanski, The Politics of Slums in the Global South: Urban informality in Brazil, India, South Africa and Peru., Singap. J. Trop. Geogr. 230 (2016) 272-273.

[5] P. Hofmann, H. Taubenböck, C. Werthmann, Monitoring and modelling of informal settlements - A review on recent developments and challenges, in: 2015 Jt. Urban Remote Sens. Event, JURSE 2015, 2015. https://doi.org/10.1109/JURSE.2015.7120513.

[6] M. Salem, N. Tsurusaki, P. Divigalpitiya, Remote sensing-based detection of agricultural land losses around greater Cairo since the Egyptian revolution of 2011, Land Use Policy. 97 (2020) 1-8. https://doi.org/10.1016/j.landusepol.2020.104744.

[7] United Nations, Sustainable Development Challenges, New York, NY, USA, 2013. https://doi.org/10.1016/j.compind.2010.10.001.

[8] M. Wurm, T. Stark, X.X. Zhu, M. Weigand, H.
Taubenböck, Semantic segmentation of slums in satellite images using transfer learning on fully convolutional neural networks, ISPRS J.

Photogramm. Remote Sens. 150 (2019) 59-69. https://doi.org/10.1016/j.isprsjprs.2019.02.006.

[9] D. Kohli, R. Sliuzas, N. Kerle, A. Stein, An ontology of slums for image-based classification, Comput. Environ. Urban Syst. 36 (2012) 154-163. https://doi.org/10.1016/j.compenvurbsys.2011.11.0 01.

[10] M. Salem, Peri-urban dynamics and land-use planning for the Greater Cairo Region in Egypt, in: WIT Trans. Built Environ., WIT Press, Waterford, Ireland, 2015: pp. 109-119. https://doi.org/10.2495/SD150101.

[11] United Nations, Goal 11 .. Sustainable Development Knowledge Platform. Targets and Indicators, (2019). https://sustainabledevelopment.un.org/sdg11 (accessed October 12, 2019).

[12] R. Vinuesa, H. Azizpour, I. Leite, M. Balaam, V. Dignum, S. Domisch, A. Felländer, S.D. Langhans, M. Tegmark, F. Fuso Nerini, The role of artificial intelligence in achieving the Sustainable Development Goals, Nat. Commun. 11 (2020) 1-10. https://doi.org/10.1038/s41467-01914108-y.

[13] R. Mahabir, A. Croitoru, A. Crooks, P. Agouris, A. Stefanidis, A Critical Review of High and Very High-Resolution Remote Sensing Approaches for Detecting and Mapping Slums: Trends, Challenges and Emerging Opportunities, Urban Sci. 2 (2018) 8. https://doi.org/10.3390/urbansci2010008.

[14] R. Mahabir, A. Croitoru, A. Crooks, P. Agouris, A. Stefanidis, A Critical Review of High and Very High-Resolution Remote Sensing Approaches for Detecting and Mapping Slums: Trends, Challenges and Emerging Opportunities, Urban Sci. 2 (2018) 8. https://doi.org/10.3390/urbansci2010008.

[15] R. Mahabir, P. Agouris, A. Stefanidis, A. Croitoru, A.T. Crooks, Detecting and mapping slums using open data: a case study in Kenya, Int. J. Digit. Earth. 0 (2018) 1-25. https://doi.org/10.1080/17538947.2018.1554010.

[16] K.K. Gadiraju, R.R. Vatsavai, N. Kaza, E. Wibbels, A. Krishna, Machine learning approaches for slum detection using very high resolution satellite images, in: IEEE Int. Conf. Data Min. Work. ICDMW, IEEE, 2019: pp. 1397-1404. https://doi.org/10.1109/ICDMW.2018.00198.

[17] C. Persello, A. Stein, Deep Fully Convolutional Networks for the Detection of Informal Settlements in VHR Images, IEEE Geosci. Remote Sens. Lett. 14 (2017) 2325-2329. https://doi.org/10.1109/LGRS.2017.2763738.

[18] S. Khorram, C.F. van der Wiele, F.H. Koch, S.A.C. Nelson, M.D. Potts, S. Khorram, C.F. van der Wiele, F.H. Koch, S.A.C. Nelson, M.D. Potts, Future Trends in Remote Sensing, in: Princ. Appl. Remote Sens., Springer International Publishing, 2016: pp. 277-285. https://doi.org/10.1007/978-3319-22560-9_9.

[19] B.J. Gram-Hansen, F. Azam, P. Helber, A. CocaCastro, P. Bilinski, I. Varatharajan, V. Kopackova, Mapping informal settlements in developing 
countries using machine learning and low resolution multi-spectral data, in: AIES 2019 Proc. 2019 AAAI/ACM Conf. AI, Ethics, Soc., Association for Computing Machinery, Inc, New York, NY, USA, 2019: pp. 361-368. https://doi.org/10.1145/3306618.3314253.

[20] S.R. Maiya, S.C. Babu, Slum Segmentation and Change Detection: A Deep Learning Approach, (2018).

[21] M. Salem, N. Tsurusaki, P. Divigalpitiya, Land use/land cover change detection and urban sprawl in the peri-urban area of greater Cairo since the Egyptian revolution of 2011, J. Land Use Sci. (2020) 1-15. https://doi.org/10.1080/1747423X.2020.1765425.

[22] A. Howeidy, D.K. Shehayeb, E. Göll, K.M.A. Halim, M. Séjourné, M. Gado, E. Piffero, G. Haase-Hindenberg, G. Löffler, J. Stryjak, J. Gerlach, M. el-Jesri, M. Fink, N.M. el-Sebai, R. Kipper, S. Sabry, V. Liebel, W. Cobbett, Cairo's Informal Areas Between Urban Challenges and Hidden Potentials, Citeseer. (2009) 115.

[23] M.A. Khalifa, Evolution of informal settlements upgrading strategies in Egypt: From negligence to participatory development, Ain Shams Eng. J. 6 (2015) 1151-1159. https://doi.org/10.1016/j.asej.2015.04.008.

[24] M. Salem, The development of deteriorating districts of historical value in Metropolitan Cities, in: Int. Conf. Munic. Manag. Urban Dev. Sustain. Arab Cities, Kuwait, 2012: pp. 1-42.

[25] J. Graesser, A. Cheriyadat, R.R. Vatsavai, V. Chandola, J. Long, E. Bright, Image based characterization of formal and informal neighborhoods in an urban landscape, IEEE J. Sel. Top. Appl. Earth Obs. Remote Sens. 5 (2012) 1164-1176. https://doi.org/10.1109/JSTARS.2012.2190383.

[26] R. Sliuzas, G. Mboup, A. de Sherbinin, Report of the expert group meeting on slum identification and mapping, Rep. by CIESIN, UN-Habitat, ITC. (2008) 36 .

[27] D. Kohli, R. Sliuzas, A. Stein, Urban slum detection using texture and spatial metrics derived from satellite imagery, J. Spat. Sci. 61 (2016) 405426. https://doi.org/10.1080/14498596.2016.1138247

[28] D. Verma, A. Jana, K. Ramamritham, Transfer learning approach to map urban slums using high and medium resolution satellite imagery, Habitat Int. 88 (2019) 101981. https://doi.org/10.1016/j.habitatint.2019.04.008.

[29] M. Kuffer, K. Pfeffer, R. Sliuzas, Slums from space-15 years of slum mapping using remote sensing, Remote Sens. 8 (2016) 455. https://doi.org/10.3390/rs8060455.

[30] J.R.B. and A.S. Nicholus Mboga, Claudio Persello, Detection of Informal Settlements from VHR Images Using Convolutional Neural Networks Nicholus, in: Remote Sens., MDPI, 2017: pp. 118. https://doi.org/10.3390.

[31] R. Liu, M. Kuffer, C. Persello, The temporal dynamics of slums employing a CNN-based change detection approach, Remote Sens. 11 (2019). https://doi.org/10.3390/rs11232844.
[32] Ministry of Housing- Utilities and Urban Communities, Greater Cairo Urban Development Strategy;Part I: Future Vision and Strategic Directions, The General Organization for Physical Planning (GOPP), Cairo, Egypt, 2012.

[33] D. Sims, Urban Slums Reports: The case of Cairo, Egypt, Case Stud. Glob. Rep. Hum. Settlements 2003. (2003) 1-24. https://doi.org/10.1029/2002GL015399.

[34] S. O'Donnell, Informal Housing in Cairo:, (2010) $1-45$.

[35] A. Kenawy, Al-ashwaiat areas in Greater Cairo Region (GCR) a Challenge for the state, 2016.

[36] M. Lesiv, L. See, J.C.L. Bayas, T. Sturn, D. Schepaschenko, M. Karner, I. Moorthy, I. McCallum, S. Fritz, Characterizing the spatial and temporal availability of very high resolution satellite imagery in Google Earth and Microsoft Bing Maps as a source of reference data, Land. 7 (2018). https://doi.org/10.3390/land7040118. 